\title{
Patient safety related incidents and daylight savings time transitions
}

J Gen Intern Med 36(4):1121

DOI: $10.1007 / \mathrm{s} 11606-021-06602-1$

(C) Society of General Internal Medicine 2021

$\mathrm{T}_{\mathrm{o}}$ o The Editor,

Journal of General Internal Medicine

Dear Editor,

We thank Drs. Rishi and Chaudhry for their letter and interest in our paper. They concur with our conclusion that this area needs to be studied further and that countermeasures to help mitigate the increased risk of safety-related incidents (SRIs) following the spring daylight savings time (DST) should be evaluated. In addition, they raise the possibility that there may be seasonal variation in the number of SRIs that could account for the findings of a significant increase in SRIs resulting from human error following the spring DST in our study.

The study that they cite from Australia demonstrated an annual cycle in the rate of SRIs in that the number of voluntary staffreported incidents peaked in October, which is spring in Australia ${ }^{1}$. The authors did not report changes following the transition into and out of DST which Australia does in fact implement. In our study, we attempted to control for time of the year effects by comparing the number of SRIs in the week following the transition into spring DST to the number of SRIs occurring in the week immediately preceding the spring transition. Similarly, we compared the number of SRIs in the week following the transition out of DST in the fall to the week immediately preceding that transition. Therefore, we believe that our methods do account for any possible time of the year effects.

Our organization has a site in the state of Arizona which does not implement DST. We did not have sufficient and comparable data from the Arizona site to conclusively evalu- ate whether or not there was a concurrent significant change in SRIs at that site. The site is much smaller than the cumulative remainder of all of the sites in the organization which are in states that implement DST and for which data were reported in our study.

Bhanu Prakash Kolla, MD FRCPysch

Brandon Coombes PhD

Timothy I Morgenthaler MD

Meghna P Mansukhani MD

Bhanu Prakash Kolla, MD, FRCPsych ${ }^{1,2}$

Brandon J. Coombes, $P h D^{3}$

Timothy I. Morgenthaler, $M D^{2}$

Meghna P. Mansukhani, $M^{2}$

${ }^{1}$ Department of Psychiatry and Psychology, Mayo Clinic,

Rochester, MN, USA

${ }^{2}$ Center for Sleep Medicine, Mayo Clinic,

Rochester, MN, USA

${ }^{3}$ Division of Bioinformatics, Mayo Clinic,

Rochester, MN, USA

Corresponding Author: Bhanu Prakash Kolla, MD, FRCPsych; Department of Psychiatry and Psychology, Mayo Clinic, Rochester, MN, USA (e-mail: kolla.bhanuprakash@mayo.edu).

\section{REFERENCE}

1. Buckley D, Bulger D. Trends and weekly and seasonal cycles in the rate of errors in the clinical management of hospitalized patients. Chronobiol Int 2012:29:947-954.

Publisher's Note: Springer Nature remains neutral with regard to jurisdictional claims in published maps and institutional affiliations. 